\title{
La música de tradición oral en los tiempos de la world music. ¿Es posible una protección legal más allá del derecho de autor?
}

Sebastian Olave Soler

Universidad Sorbonne-Université, IberHis, Paris, Francia sebastiansoler@laposte.net

Recepción: septiembre 2019. Aceptación: diciembre 2019.

\section{Resumen}

La propiedad intelectual, tal como ha sido definida por el derecho occidental, ha tendido a ignorar las especificidades y multiplicidades de la creación musical. Los mecanismos diseñados a partir de esta concepción, basados en la invariabilidad de los textos y en el aprovechamiento económico, han favorecido un sistema que permite el uso indiscriminado de expresiones comunitarias, en particular de las músicas de tradición oral. A través de las nociones de autenticidad y de propiedad artística, este artículo reflexiona sobre la necesidad de ampliar y adaptar el derecho de propiedad intelectual, en la búsqueda de mecanismos de protección para dichas músicas, que tengan en cuenta sus particularidades artísticas y sociales.

Palabras clave: música tradicional, world music, autenticidad, propiedad intelectual

\section{A música de tradição oral em tempos de world music. É possível uma proteção legal para além dos direitos de autor?}

\section{Resumo}

A propriedade intelectual, de acordo com o direito ocidental, tende a ignorar as especificidades e multiplicidades da criação musical. Os mecanismos projetados a partir dessa concepção, baseados na invariabilidade dos textos e no proveito económico, favoreceram um sistema que permite o uso indiscriminado de expressões comunitárias, em particular das músicas 
de tradição oral. Fazendo uso das noções de autenticidade e propriedade artística, este artigo reflete sobre a necessidade de ampliar e adaptar o direito de propriedade intelectual, na busca de mecanismos de proteção para essas músicas, levando em consideração as suas peculiaridades artísticas e sociais.

Palavras-chave: música tradicional, world music, autenticidade, propriedade intelectual

\title{
The Music of Oral Tradition in the Times of World Music. Is Legal Protection Possible Beyond Copyright?
}

\begin{abstract}
Intellectual property, as defined by Western law, has tended to ignore the specificities and multiplicities of musical creation. The mechanisms designed from this conception, based on the invariability of the texts and on economic exploitation, have favored a system that allows the indiscriminate use of community expressions, in particular of those of the music of oral tradition. Through the notions of authenticity and artistic property, this article reflects on the need to expand and adapt the intellectual property right, in the search for protection mechanisms for this type of music, which take into account their artistic and social peculiarities
\end{abstract}

Keywords: Traditional music, world music, authenticity, intellectual property

"They say 'ah, no. You have no right to do that, put synthesizers on our music'.

I say why? 'Why can't I do that? Give me a good reason'.

And of course they have no good reason". ${ }^{1}$

Éric Mouquet ${ }^{2}$

\section{Introducción}

La música se mueve, desde que existe, al ritmo de los músicos que la han llevado a todas partes con ellos. Esta es una de las principales características

\footnotetext{
${ }^{1}$ Citado en Mallet (2002, p. 837).

${ }^{2}$ Creador e integrante del grupo francés Deep Forest, de gran éxito en la década de 1990.
} 
de un arte cuya esencia es volátil e inaprensible. El ritmo del mundo de hoy, por otra parte, ha implicado que los intercambios generados a partir de este movimiento no solo se hayan acelerado, sino que sus modelos se hayan modificado y que las fuerzas de sus distintos actores se hayan desequilibrado. La globalización de los mercados, la masificación de los productos artísticos, la televisión, los discos, el internet y, en general, un cierto uso de los sistemas que permiten que la música se mueva independientemente de los hombres que la producen, han transformado la manera en que la música es concebida y percibida. En este contexto, las músicas tradicionales son especialmente proclives a una banalización producto de la transformación de expresiones culturales en bienes de consumo. La industria del disco ha buscado, antes que el testimonio de la diversidad cultural, un retrato colorido que encaje en los presupuestos extravagantes de lo que se supone que es la música extra-europea, favoreciendo así una "espectacularización" de las expresiones tradicionales. La world music, en particular, retiene virtuosos carismáticos, instrumentos singulares, sonoridades extrañas... características aisladas que supedita a las estructuras y tendencias dominantes del mercado, subrayando su carácter desconocido, peculiar y distintivo: "se abandona el lenguaje vivo de los ritmos tradicionales, tal como son interpretados en su medio original, para pasar al mundo de la puesta en escena" ${ }^{3}$ (Zanetti 2005, p. 100). ${ }^{4}$ Los productores de la world music, creen en efecto, como se desprende de la afirmación de Éric Mouquet, que todo aquello que es posible les es permitido.

Teniendo en cuenta, como afirma Peter Jaszi (2017), que dos de las deficiencias más importantes de las leyes de derechos de autor y del sistema de propiedad intelectual se relacionan con la atribución y el control de las músicas tradicionales, este artículo pretende examinar las nociones de autenticidad y propiedad artística, como elementos a través de los cuales podría ser posible suscitar una confluencia del derecho occidental con la protección efectiva del acervo musical tradicional.

\section{Apropiación cultural y economía de mercado}

La world music, como su misma designación lo indica, se quiere ecuánime, pluralista y multicultural, representante de los valores posmodernos. Promete unir los pueblos y desafiar las obsoletas fronteras políticas a

\footnotetext{
${ }^{3} \mathrm{~A}$ menos que se indique expresamente lo contrario, siempre nuestra traducción.

4 “On quitte le langage vivant des rythmes traditionnels, tels qu'ils sont joués dans leur milieu originel, pour passer dans le monde de la mise en scène".
} 
través de la diversidad cultural del planeta. La realidad, por otra parte, nos muestra que es una categoría con la cual se ha buscado equiparar bajo la etiqueta "exótico" músicas de los orígenes más diversos. Con esta homogeneización, las expresiones culturales son convertidas en mercancía, supeditadas a la aprobación de un público extranjero y pasan a ser regidas por los estándares de la economía de mercado occidental. En consecuencia, los músicos, cualquiera que sea su cultura de origen, "deben respetar un cierto número de reglas específicas del mundo del espectáculo, que no concuerdan sino parcialmente con los cánones de la tradición de la que provienen" (Aubert, 2005, p. 117). ${ }^{5}$

Las empresas que definen dicha categoría y comercializan a través de ésta se valen, además de los estereotipos, de los avances tecnológicos, de la difusión masiva y sobretodo de la supremacía económica de Occidente. El poder político y económico de las potencias occidentales -en particular Estados Unidos, Francia y Reino unido- se refleja en la disparidad de fuerzas característica de la world music. ${ }^{6}$ Ana María Ochoa afirma que "como en el encuentro colonial [en la world music] es el músico del primer mundo el que tiene la posibilidad de abrirle (o cerrarle) las puertas a los músicos y sonoridades provenientes de África, Asia o América Latina” (2003, p. 31). Con el triunfo del modelo económico estadounidense han proliferado una serie de fenómenos que han acelerado los mestizajes y alterado la relación entre lo local y lo global. Es cierto que las expresiones culturales se han mezclado y las artes se han contrapuesto, cuestionado e influenciado recíprocamente mucho antes de que esto fuera suscitado por los estándares de una economía globalizada. El mestizaje no equivale necesariamente a la homogeneización, ni la protección de las identidades locales su inequívoca contraparte. La mezcla se convierte en uniformización cuando es solo una forma de caracterizar una mercancía, cuando los objetos comienzan a apreciarse únicamente por el valor de su posición en el mercado. ${ }^{7}$ Como ha señalado Serge Gruzinski, "incluso si reconocemos

\footnotetext{
5 “[...] se doivent de respecter un certain nombre de règles particulières au monde du spectacle, qui ne recoupent que partiellement les canons de la tradition dont ils sont issus".

${ }^{6}$ Como señala Henri Lecomte: “Estamos justo en medio de la arrogancia de Occidente quien, amo del mundo económico, se cree también capaz de aportar sangre nueva a unas músicas de las que tiene un enfoque totalmente superficial" (2005, p. 142).

${ }^{7}$ La teoría marxista lo denomina "valor de cambio" (o de intercambio). Adorno, en referencia a esta transformación de las expresiones culturales, se expresaba de la siguiente manera: “[...] Este ámbito [el cultural] aparece precisamente en el mundo de las mercancías como ajeno a las restricciones del intercambio, como un ámbito en el que sólo existe un vínculo inmediato con las mercancías. Esta es, sin embargo, la única ilusión a la cual las mercancías culturales deben su valor de cambio. [...] El puro valor de uso del cual las mercancías culturales deben mantener la ilusión en nuestra sociedad, de un extremo al otro capitalista, es ahora reemplazado por el puro valor de intercambio, que, aunque permanece como tal, garantiza de manera engañosa la función del valor de uso" (2001, pp. 30-31).
} 
que todas las culturas son híbridas y que las mezclas se remontan a los orígenes de la historia del hombre, no sabríamos por esto trasladarlo a la formulación de una nueva ideología derivada de la globalización" (2002, p. 36). ${ }^{8}$ De este modo, las prácticas tradicionales corren el riesgo de fundirse en el mundo de la oferta y la demanda en el cual las características estéticas se convierten únicamente en un certificado de proveniencia que las hace más o menos atractivas frente a los mercados potenciales.

Ahora bien, es evidente que todo cambio en el esquema concepción-creación-ejecución-uso significa una alteración en las cualidades semánticas de las formas artísticas. Descontextualizar unas músicas ancladas a unas determinadas prácticas comunitarias por ejemplo, equivale a desconocer deliberadamente la voluntad y las aspiraciones de aquellos que las crean y el rol que dichas músicas juegan en las dinámicas sociales. Es importante recordar en este sentido que, en las comunidades tradicionales, la música cumple una función que sobrepasa el entretenimiento; ésta hace parte de un acervo cultural que se desarrolla simultáneamente con la comunidad misma. T.S. Eliot afirma que en los estados primarios de organización social las diversas actividades están entrelazadas de una manera inextricable: "A medida que la civilización se torna más compleja, una mayor especialización ocupacional se hace evidente [...] Es solo en una etapa mucho más avanzada que la religión, la ciencia, la política y el arte se conciben de manera abstracta, separados unos de otros" (1961, p. 24). ${ }^{9}$ Así, la mayor parte de la música que es comercializada hoy bajo la etiqueta "world music" menoscaba los principios de unas tradiciones musicales que se explican únicamente a partir de formas singulares de entender el mundo y de relacionarse con él.

Si la contradicción de someter dichas expresiones a las nociones de mercado, propiedad privada y comodificación parece no atañer a los productores de la world music, los organismos internacionales encargados de gestionar las leyes relativas a la propiedad intelectual se han cuestionado por su parte, al menos desde 1950, si las expresiones culturales tradicionales deben ser protegidas por normativas transnacionales y eventualmente la manera de hacerlo (Jaszi, 2017). No obstante, la legislación relativa al copyright sigue siendo limitada en este aspecto, y continúa considerando

\footnotetext{
8 "Même si l'on reconnaît que toutes les cultures sont hybrids et que les mélanges remontent aux origins de l'histoire de l'homme, on ne saurait le ramener à la formulation d'une idéologie nouvelle issue de la globalization".

9 "As civilisation (sic) becomes more complex, greater occupational specialization evinces itself [...] it is only at a much further stage that religion, science, politics and art become abstractly conceived apart from each other".
} 
las músicas tradicionales como de dominio público y por lo tanto copyrightfree. Simha Arom es categórico al afirmar que "los textos de ley existentes se han revelado totalmente inadaptados a las concepciones y prácticas musicales que prevalecen en las sociedades de tradición oral" (Arom y Martin, 2015, p. 124). ${ }^{10}$ La Convención de Berne por ejemplo, estipula simplemente que las obras musicales no serán protegidas a menos que sean "obras originales" y que "hayan sido fijadas en algún tipo de soporte físico ${ }^{11}$ (some material form)". ${ }^{12}$ Esta definición excluye -además que problematiza otras formas musicales- las creaciones y recreaciones tradicionales, colectivas y orales de la música. ${ }^{13}$

Es flagrante que las nociones y disposiciones que han sido concebidas dentro del marco de las leyes de propiedad intelectual no han sido confeccionadas para proteger el legado cultural de las prácticas artísticas, sino que han sido destinadas a individualizar la creatividad y la propiedad, rentabilizar las creaciones y regular su usufructo comercial. El copyright es un "Instrumento de comodificación dentro de los sistemas capitalistas" confirma Anthony McCann (1998, p. 7), mientras que las expresiones culturales tradicionales son concebidas dentro de prácticas sociales y valores comunitarios que no son tenidos en cuenta por el sistema de mercado. Peter Jaszi admite que "la ausencia de un convenio internacional sobre la protección de las expresiones culturales tradicionales es una brecha estructural mayor en el derecho internacional" (2017). ${ }^{14}$ En efecto, el hecho de que las comunidades tradicionales no conciban la propiedad y la originalidad de la misma manera que la jurisprudencia occidental no significa que éstas no estén interesadas en salvaguardar sus prácticas artísticas de usos que consideren inapropiados. ${ }^{15}$

\footnotetext{
10 “[...] les textes de lois existentes se sont rélévés totalement inadaptés aux conceptions et et aux pratiques musicales qui prévalent dans les sociétés de l'oralité".

${ }^{11}$ La Convención de Roma de 1961 permitía a ejecutantes e intérpretes impugnar de grabaciones y radiodifusiones que éstos no hubieran expresamente aceptado. Sin embargo, la aplicación de esta normativa a entornos no-Occidentales es nuevamente omitida, teniendo en cuenta que la Convención de Roma se elabora a partir de las definiciones de la Convención de Berne.

${ }^{12}$ Berne Convention for the Protection of Literary and Artistic Works (1886), Artículo 2. Recuperado de https://www.wipo.int/treaties/.

${ }^{13}$ Así mismo impide el derecho para autorizar, refutar o impugnar cualquier tipo de radiodifusión o grabación -o cualquier alteración de la obra-, los derechos morales, o el derecho a obtener una remuneración equitativa, consignados en los artículos 6, 11, 12 y 13 de la Convención de Berne.

14 “The absence of an international agreement on the protection of traditional cultural expressions is a major structural gap in international law".

${ }^{15}$ Recordemos por ejemplo los reiterados casos de comunidades aborígenes australianas (ver Janke, 2003), del pueblo Navajo (ver Yazzie, 2008 o Bsumek, 2016), de las poblaciones de origen africano en Cuba (ver Moore, 2002), o bien del pueblo Nahua, que conciben la innovación como una transgresión de esencia diabólica (Hémond, 2013).
} 
Todavía hoy, virtualmente cualquier persona puede expoliar, modificar, grabar y vender a su voluntad material musical tradicional. ${ }^{16}$ Éste resulta mutilado y adaptado a las formas dominantes de difusión y escucha de la música en Occidente: la armonía y el ritmo son simplificados; la extensión de las piezas limitadas a los estándares de la radio; los ritos y ceremonias convertidos en piezas de concierto... es la economía globalizada y no las realidades sociales aquello que determina las modalidades y morfologías de la música. Esta mercantilización de las creaciones culturales, como bien afirma Adorno, no viene sin repercusiones. Además de los cambios evidentes en las propias estructuras musicales:

\section{[...] el cambio de función de la música afecta los elementos constitutivos de la relación entre el arte y la sociedad [...] Las obras que sucumben a la fetichización y se convierten en mercancías culturales sufren de esta manera modificaciones constitutivas. Son pervertidas. Una consumación incoherente las degrada (2001, pp. 31-35). ${ }^{17}$}

Teniendo en cuenta lo anterior, y a pesar de que la extensión de este artículo no permite abordar en profundidad el debate de la apropiación cultural o de la propiedad intelectual, consideramos que es pertinente examinar las nociones de autenticidad y propiedad artística como herramientas a través de las cuales las creaciones colectivas tradicionales pueden contrarrestar los procedimientos de la industria del disco. No se trata por supuesto de proteger un estado de "pureza ideal", de condenar los mestizajes o de negar la naturaleza móvil y ambigua de la cultura misma. Se trata de discutir una "objetabilidad" estética y moral que pueda ser utilizada para devolver la potestad sobre sus prácticas a las comunidades y hacer eventualmente convergir bajo un mismo marco jurídico los derechos de las comunidades tradicionales y la legislación occidental. ${ }^{18}$

\footnotetext{
${ }^{16}$ Podríamos de nuevo nombrar como ejemplo el caso de Deep Forest que a partir de la apropiación de material aborigen (principalmente del África noroccidental y de las Islas Salomón, aunque no limitado a éstos), logró un éxito comercial extraordinario: además de recibir el disco de oro en Francia, "permaneció en la top-list de la revista Billboard durante 25 semanas, había vendido más de dos millones de copias para mayo de 1995 y recibió una nominación al Grammy. Las rentables regalías se han acumulado a medida que Porsche, Sony TV, Coca-Cola y otras importantes compañías han incorporado música de Deep Forest a sus campañas publicitarias" (Mills, 1996, p. 59, citado en Zemp, 1996, p. 46).

17 "Le changement de fonction de la musique touche aux éléments constitutifs du rapport de l'art et de la société [...] Les ouvres qui succombent à la fétichisation et deviennent des marchandises culturelles subissent ainsi des modifications constitutives. Elles sont perverties. Une consommation incohérente les dégrade".

${ }^{18}$ Una reflexión similar dio lugar a la noción de bio-piratería (biopiracy) que ha logrado un debate que ha impulsado la concepción de un marco legal que regule la explotación y proteja la biodiversidad. A pesar de que muchos de los aspectos más controversiales no han sido todavía delimitados, como indica Janna Rose “Desde 1994, el Acuerdo sobre los Aspectos Relacionados con el Comer-
} 


\section{Autenticidad, creatividad y tradición}

La grabación y distribución de músicas tradicionales han sido justificadas como la manera de salvaguardar formas culturales que de otra manera podrían desaparecer. Hugo Zemp, etnomusicólogo y editor del sello disquero Le Chant du monde, afirma sin embargo que "si la iniciativa no proviene de los propios músicos y cantantes, y si ya no existe el contexto social de la música tradicional, sea en Suiza o en el Pacífico Sur, ya no estarán reunidas las condiciones para que una música subsista" (citado en Borel, 1996, p. 300). ${ }^{19}$ Esta afirmación deja entrever una de las características más importantes de la música, frecuentemente pasada por alto: la música es ante todo un hecho social; ${ }^{20}$ es una organización determinada de los sonidos, aceptada a nivel social y por lo tanto socialmente específica. De tal manera que la música como expresión y producto de una cultura, fuera de este contexto no puede ser sino una muestra parcial y deformada que menoscaba así sus estructuras discursivas. Como subraya T.S. Eliot, la cultura es construida por la acción y la interacción de grupos humanos, "[la cultura] es una cosa que no podemos alcanzar deliberadamente. Es el producto de una variedad de actividades más o menos armoniosas, cada una ejercida por su propio interés" (1961, p. 19). ${ }^{21}$

Así pues, la autenticidad y la propiedad son consideradas aquí a la vez como un derecho y una cualidad inherentes a las culturas. Primero, la autenticidad de las prácticas artísticas propias a un cierto grupo social como fruto del desarrollo dentro de los límites de una cultura determinada. Luego, la cualidad de "auténtico" traducida en la propiedad exclusiva de los elementos constitutivos de dichas prácticas: patrones, motivos, instrumentos, tipos de canto, formas narrativas, cosmogonías, etc. Estos dos

cio de los Derechos de Propiedad Intelectual (Agreement on Trade-Related Aspects of Intellectual Property Rights) ha exigido a los países miembros de la OMC que desarrollen marcos legales para proteger las variedades de recursos vegetales y animales [...] Desde principios de la década de 2000, muchos gobiernos nacionales han modificado sus leyes para proteger sus recursos biológicos, de conformidad con el Convenio de 1992 sobre la Diversidad Biológica" (Rose, 2016). La autenticidad y la propiedad asociada a ésta podrían utilizarse de una manera similar.

19 "Si l'initiative ne vient pas des musiciens et des chanteurs eux-mêmes, que ce soit en Suisse ou dans le Pacifique Sud, et que le contexte social de la musique traditionnelle n'existe plus, les conditions pour qu'une musique perdure ne sont plus réunies".

${ }^{20}$ Jean Molino concibe la música como hechos sociales totales (faits sociaux totaux): "las actividades que corresponden a los diversos componentes de la música no son el resultado de individuos aislados sino que tienen lugar en grupos, constituyendo así [...] hechos sociales totales" (2009, p. 424). De esto se desprende, explica Molino, la triple naturaleza de la obra artística -la poiética (creativa), la material o inmanente (objetiva) y la estésica (perceptiva/subjetiva)-, que está a la base de la construcción simbólica y de la inalienable cualidad social de la música.

21 "[...] culture is the one thing that we cannot deliberately aim at. It is the product of a variety of more or less harmonious activities, each pursued for its own sake". 
conceptos entran en juego al evaluar el valor estético y particularmente la responsabilidad moral atribuible a producciones cuyas prácticas no tengan en consideración las construcciones simbólicas originarias. La noción de autenticidad será desarrollada a partir del trabajo de James 0. Young, ${ }^{22}$ en particular a partir del argumento denominado Cultural Experience Argument que valora la autenticidad de la obra y del artista poniendo en relación sus métodos y materiales con los desarrollos culturales: "la capacidad de usar un estilo de forma exitosa está vinculada a la participación dentro de la cultura [...] los artistas que carecen de los antecedentes culturales necesarios están abocados a producir obras o actuaciones de escasa calidad estética" (2008, pp. 34-36). Este argumento es utilizado para defender, por ejemplo, el derecho exclusivo de la población afroestadounidense para producir e interpretar el blues (o para interpretarlo bien), dado que sólo a través de la experiencia personal a nivel económico, cultural, social y emocional podría este género ser comprendido como expresión de la discriminación de la que la población negra fue objeto. Bajo esta premisa, el blues producido por "blancos", será una expresión inauténtica. En el libro Cultural Appropriations and the Arts, James O. Young distingue en este sentido al menos tres tipos de autenticidad aplicables en este contexto.

Autenticidad de proveniencia

La primera categoría es denominada "autenticidad de proveniencia" (Provenance authenticity): "podemos decir que una obra es auténtica cuando está en un estilo y género de una cultura determinada y que ha sido producida por insiders" ${ }^{23}$ (2008, p. 46). ${ }^{24}$ Este es tal vez el principal argumento en contra de la apropiación indebida por parte de la industria musical. Como en el caso del blues, esta postura sugiere que la interpretación o la creación por personas que o bien desconocen las particularidades de las representaciones culturales, no entienden su lugar en la construcción social o simplemente no perciben las sutilezas de la prácticas musicales, no podrán crear (o recrear) obras legítimas dentro de dicho género.

Si bien es cierto que es difícil pretender el confinamiento geográfico de la música y la construcción de una consideración estética basada exclusivamente en la proveniencia de una obra, la estrategia de la world music

\footnotetext{
${ }^{22}$ Particularmente Cultural Appropriations and the Arts (2008) y "Nothing Comes from Nowhere": Reflections on Cultural Appropriation as the Representation of Other Cultures (2009).

${ }^{23}$ Young define los insiders como artistas que crean obras de acuerdo a las prácticas de la cultura a la que pertenecen, mientras que los outsiders son aquellos que producen obras en el estilo de culturas ajenas a su propia cultura.

24 "We may say that a work is authentic when it is in a style and genre of a given culture and insiders have produced it".
} 
-común a todas las industrias de contenidos mainstream-, ${ }^{25}$ sumado al inmenso poder de propaganda y distribución de las grandes casas disqueras, ${ }^{26}$ amenaza de manera cierta la realidad de las expresiones tradicionales. La inautenticidad, en este caso, tiene repercusiones directas sobre el propio material musical y en consecuencia sobre las construcciones de sentido alrededor de éste. La música sagrada del culto orisha del pueblo yoruba, para ilustrar este caso, es utilizada en medio de rituales sagrados en los cuales los instrumentos musicales son intermediarios entre la población y sus deidades: cada tambor y cada patrón rítmico tiene una significación y un rol precisos en medio de las ceremonias religiosas. La comercialización o el uso abusivo -grabarlas y extraerlas de su contexto sacro constituye de por sí una violación a la privacidad y a las creencias de estas comunidades-, que conlleve además la profanación de símbolos sagrados, puede resultar ofensiva para esta comunidad e incluso llevar a una deformación de los valores sociales aglutinantes. Sabemos que las interpretaciones con mayor fuerza de difusión tienden con el tiempo a imponerse como la manera adecuada de producir e interpretar un determinado género. Si los insiders "comienzan a verse a sí mismos como los ven los demás [...] y comienzan a ejecutar sus expresiones artísticas del mismo modo que los outsiders" (Young 2008, p. 118), ${ }^{27}$ el resultado puede ser la destrucción de las características distintivas de una cultura.

\section{Autenticidad personal}

La segunda categoría de Young es denominada "autenticidad personal" (Personal authenticity). Se refiere a la obra de arte resultado del "genio individual de un artista" (2008, p. 47). ${ }^{28}$ Ésta plantea que las obras producidas a través de la simple apropiación serían obras de pobre valor estético puesto que imitan o se derivan de estilos o motivos tradicionales. A pesar

\footnotetext{
${ }^{25}$ Fréderic Martel lo denomina "diversidad estandarizada (diversité standarisée)" (2010, p. 424) у a pesar de la contradicción aparente, sintetiza el método utilizado para vender un tipo de producto a la mayor cantidad de personas posible, mezclando una base similar con pequeñas variantes locales. Martel resume de esta manera la homogeneización que resulta de un procedimiento que busca la audiencia en masa y que privilegia "la estructura de la canción sobre su invención musical [...] los efectos de similitud entre grupos y una melodía que podemos cantar, como si ya la hubiéramos oído" (2010, p. 118).

${ }^{26} \mathrm{~A}$ pesar de presentarse como pequeños sellos independientes con propósitos altruistas, éstos son en realidad filiales de las grandes casas disqueras (ver Martel, 2010). De acuerdo a su página web, el sello Real World de Peter Gabriel afirma que fue fundado "para proporcionar a artistas talentosos de todo el mundo acceso a las instalaciones de grabación más modernas y a audiencias más allá de su región geográfica". Este sello en realidad nació dentro de Virgin Records y hace parte actualmente de Universal, por lo tanto sujeto a las dinámicas ordinarias de la industria discográfica.

27 “ [...] if insiders begin to see themselves as others see them [...] and begin to practice their arts in the manner of outsiders. In either case, the insiders are threatened by assimilation".

28 "An artist's individual genius".
} 
de que esta noción se relaciona tangencialmente con la idea de creación más colectiva de las expresiones tradicionales, ${ }^{29}$ hay al menos dos razones por las cuales es pertinente su discusión aquí.

En primer lugar, porque como mencionábamos previamente, el marco legal sobre la propiedad intelectual se ha construido sobre una noción individualista de la creación que evita la compleja discusión de los estándares subjetivos y circunscritos de la originalidad y la creatividad. Es por lo tanto oportuno cuestionarnos si el uso de un patrón o la reutilización de un motivo, de manera consciente o no, convierte necesaria y automáticamente una obra en derivativa y por ende inauténtica, teniendo en cuenta que incluso los artistas más sobresalientes han evolucionado a partir de una cierta base cultural. ${ }^{30}$ Young subraya que "las obras de arte pueden deber mucho a obras existentes y seguir siendo personalmente auténticas" (2008, p. 48). ${ }^{31}$ En efecto, ejemplos abundan en la historia de la música: Debussy, quien rompe con el estilo decimonónico inspirado en el gamelán balinés; Piazzolla creador del Tango nuevo, a medio camino entre la tradición y la vanguardia... La originalidad, como la pureza, es relativa y no nos remite sino de manera accesoria a objeciones morales.

En segundo lugar, porque en la world music es habitual que las estructuras de las músicas populares en Occidente sean superpuestas a algunos elementos característicos de las músicas tradicionales. No obstante, la cultura no es un bien que pueda simplemente ser reconfeccionado y exportado: "la trasmisión de la cultura nunca puede ser el objeto directo de ninguna de nuestras actividades prácticas; lo único que podemos hacer es tratar de tener en cuenta que todo lo que hagamos afectará nuestra propia cultura o aquella de otras personas" (Eliot, 1961, p. 65). ${ }^{32}$ Si bien discos como Rei Momo (1989) de David Byrne, Ribbons (2017) de Justin Adams o Radio Bakongo (2003) de Batata, por nombrar sólo algunos, podrían ser considerados como auténticos -son personales y elaborados con insiders-, y sin duda artísticamente válidos, el resultado al final será culturalmente

\footnotetext{
${ }^{29}$ Vale la pena notar que ciertas tradiciones aborígenes australianas por ejemplo, consienten la creación individual y la "innovación" dentro de los límites de la cultura (ver Janke, 2003).

${ }^{30}$ Ferruccio Busoni (1866-1924) por ejemplo, tenía en este sentido una visión particular de la composición. Para él, el acto creativo no era sino la re-organización de materiales de por sí limitados: el hombre no puede crear de la nada y por lo tanto toda música "existe" previamente en alguna forma. La creación resulta entonces, en cierta medida, forzosamente derivativa (Knyt, 2010; Busoni, 1910).

31 "[...] artworks can owe a great deal to previously existing works and still be personally authentic".

32 "The improvement and transmission of culture can never be the direct object of any of our practical activities: all we can do is to try to keep in mind that whatever we do will affect our own culture or that of some other people".
} 
inauténtico teniendo en cuenta que éstos no se corresponden con las interacciones que originan las expresiones tradicionales ni con los códigos que las explican.

Así pues, ni la apropiación ni la superposición garantizan la autenticidad pero tampoco conllevan la objeción moral. En este contexto, la apropiación podría ser reprobada cuando dé lugar a una deformación de las prácticas tradicionales, a la asimilación por parte de la cultura dominante, e incluso a un perjuicio económico. David Byrne y La Sonora Matancera utilizaron ambos patrones rítmicos provenientes de la tradición yoruba-afrocubana. Sin embargo, Marching Through the Wilderness y Elegua quiere tambó son ejemplos diametralmente opuestos. ${ }^{33} \mathrm{Si}$ los insiders a fuerza de escuchar a Byrne modificaran sus hábitos de producción, creación y percepción, estaríamos frente a una deformación y asimilación condenables desde la discursividad de la autenticidad. Los trabajos de los outsiders pueden ser originales e innovadores -de acuerdo a sus propios cánones. Sin embargo, la evaluación estética, el sentido y el valor moral serán determinados por el contexto en el que se inscriba la obra-. El público y en consecuencia el objeto significante no será el mismo en un festival en París, en un resguardo indígena o una plaza en Buenos Aires.

Autenticidad de estilo

El tercer y último tipo de autenticidad que consideramos oportuno discutir aquí es la "autenticidad de estilo" (Style authenticity). Una (re)creación auténtica es aquella que respeta las intenciones de composición o las condiciones sociales de concepción. De todas las categorías ésta es probablemente la que puede acercarse de manera más concreta a una cualidad estética: "fracasar en la correspondencia entre el estilo de la composición y el estilo de la interpretación es un defecto estético" (Young, 2008, p. 54). ${ }^{34}$ Así mismo, esta categoría es la que más directamente podemos relacionar con el contexto de producción de la obra. Para definir la autenticidad de estilo se hace indispensable la consideración de la tradición artística, las prácticas interpretativas, el objetivo y tipo de producción, los materiales utilizados, las condiciones de ejecución, los mecanismos de mediación, etc. De tal suerte que, a partir de estas características, se distinguirán las creaciones auténticas de aquellas que no lo son. De esta manera, por

\footnotetext{
${ }^{33}$ Para llevarse una idea, no hace falta más que considerar los textos de ambas canciones. Byrne: Money doesn't matter/Babies never lie/I'm going in the out door/ I'm doing all right. Sonora Matancera: Tambó, tambó, tambó/No hay Orisha como Elegua Palainlé/po'que siempre 'ta owé /Oshun tiene siete saya/ Oshun tawedewedé/ y yo como soy su amo'/ siempre e'toy muy contentica.

34 "A failure to match style of composition and style of performance is an aesthetic flaw".
} 
ejemplo, se podría rechazar la puesta en escena de un outsider negligente que reproduzca representaciones inexactas de una práctica musical particular.

Es importante tener en cuenta que esto no significa que sean únicamente los insiders aquellos capaces de ejecutar un repertorio que les es específico. Así como las técnicas de interpretación de la música antigua son ahora estudiadas y dominadas, las sutilezas de una interpretación tradicional pueden ser, hasta cierto grado, comprendidas. Por otra parte, el hecho que los outsiders hayan dominado un estilo y sean capaces de recrearlo con un resultado satisfactorio, no significa que éste sea auténtico ni estéticamente irreprochable. Podemos citar en este sentido la fanfarria francesa Belle Image. Esta agrupación se interesó desde mediados de los años 1990 por la música denominada "pelayera" del litoral atlántico colombiano y buscó entender sus particularidades estilísticas a través, entre otros, de talleres con músicos colombianos en Francia. ${ }^{35}$

A pesar de su aparente éxito, ${ }^{36}$ las divergencias con la ejecución tradicional de esta música son evidentes. ${ }^{37}$ No solo en los patrones rítmicos, la improvisación melódica y rítmica, la composición organológica y la interpretación instrumental, sino de igual manera, en el vestuario y la puesta en escena que remite al "art de la rue" francés y no a la fiesta del caribe colombiano. La repetición de estereotipos ${ }^{38}$ y la tendencia a agrupar las expresiones no-europeas en un reductivista discurso de alteridad, dejan en evidencia la inautenticidad de esta propuesta.

\footnotetext{
${ }^{35}$ En particular con Miguel Emiro Naranjo y Rubén López "bombo mocho", miembros fundadores de la reconocida banda 19 de Marzo de Laguneta (Córdoba).

${ }^{36}$ Esta banda llegó a hacer parte de una de las festividades más importantes del litoral atlántico colombiano: las corralejas del 20 de enero de Sincelejo.

${ }^{37}$ Para nombrar sólo una de las mas obvias, en el primer corte del disco Pachamama Coronada -“Navidad Negra"-, así como en su espectáculo en vivo del mismo nombre, se utilizan tres gaitas hembra mezcladas con instrumentos de viento europeos, cuando la usanza tradicional es una sola gaita hembra y una gaita macho; los tambores tradicionales, alegre y llamador, son remplazados por congas; y en adición, esta melodía hace parte de una tradición interpretativa que ya no incluía las gaitas.

${ }^{38}$ Dentro de la descripción de uno de sus espectáculos se leen por ejemplo lugares comunes como "percusiones caribeñas provocadoras de alegría" o la "voluptuosidad de la danza sudamericana". De igual manera, las ilustraciones de sus discos suelen ser creadas a partir de una superposición de varios clichés asociados a la América Latina. En la carátula de Pachamama Coronada (ver imagen 1), un disco de música del caribe colombiano (que dicho sea de paso, no acredita los creadores originales), con título de una divinidad Inca, son utilizados símbolos de tradiciones mexicanas, peruanas y colombianas, entre otras.
} 


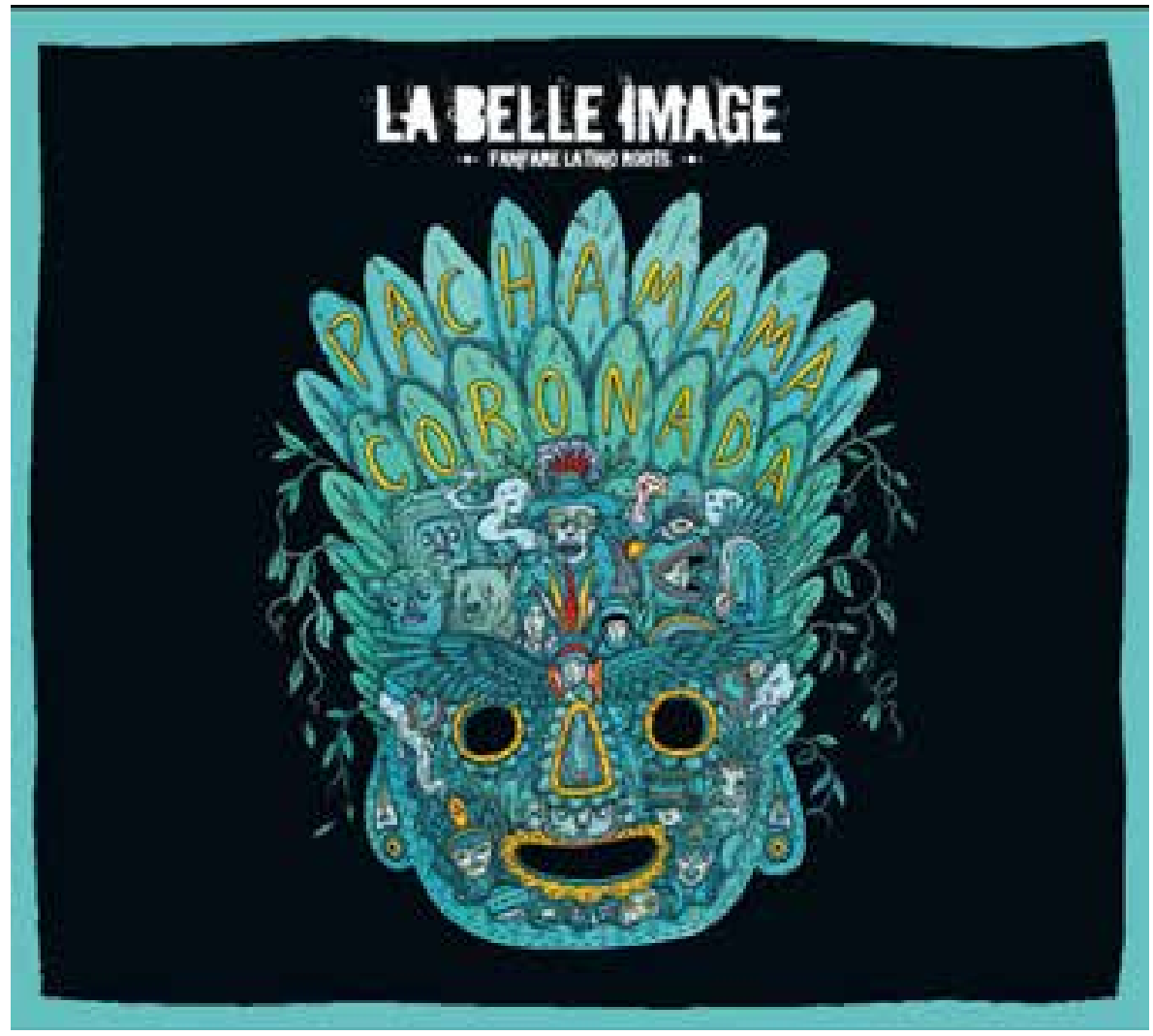

Imagen 1. Carátula de uno de los disco de Belle Image.

Sin embargo, la reinterpretación de un repertorio particular no es necesariamente condenable. Por otra parte, la destrucción de unas prácticas culturales por apropiación, asimilación o aculturación nos enfrenta, al menos, con un dilema moral. La inautenticidad de estilo tendrá sin duda repercusiones directas en la ejecución, y en consecuencia, en la manera en que las características de estas músicas podrán ser apreciadas. Una experiencia cultural insuficiente condicionará la construcción musical y por ende tenderá a desdibujar la construcción semántica. La masificación de una interpretación deficiente creará a su vez una imagen errónea de dichas expresiones y por lo tanto de la cultura que las origina. Si, por ejemplo, las bandas colombianas empezaran a adoptar las características de ejecución de la belle image porque les permite producirse por fuera del país y generar mayores ingresos, se comprometería la integridad de las propias tradiciones interpretativas a partir de una apropiación indebida. 


\section{Conclusión: autenticidad y propiedad intelectual}

Como hemos mencionado a lo largo de este texto, la propiedad intelectual y el copyright están enmarcados por las construcciones dialécticas del derecho occidental. Esto significa que la protección de las expresiones artísticas tradicionales se ha construido principalmente a partir de concepciones culturales que relegan o ignoran las modalidades específicas de las minorías étnicas. En este sentido, Michael Brown asegura que no es posible suprimir la distinción entre una idea y su realización material -sobre la cual se construye la protección legal de la propiedad intelectual-, así como la incompatibilidad de una sociedad que defiende el flujo libre de la información con un sistema que defina la propiedad a partir del origen étnico, equiparándolo con un "apartheid de la mente" (1998, p. 204). ${ }^{39}$ Sus ideas evidencian las discrepancias que surgen entre la defensa de una cultura mayoritaria y la obligación de adaptarse a ésta, y el reconocimiento de modos de existencia diferentes. Si los lineamientos sobre qué y cómo es susceptible de ser protegido se establecen a partir de ideas similares, una visión unívoca y monolítica de las realidades sociales resulta favorecida.

Esta postura ha generado considerables vacíos dentro de la protección de las prácticas tradicionales ya que no se han tenido en cuenta sus concepciones culturales específicas, como la noción de originalidad, propiedad y creación colectiva, entre muchas otras. Como bien afirma Terry Janke, la única manera de abordar una discusión que pueda conducir a una protección efectiva de estas expresiones es tomando como punto de partida las comunidades mismas y sus construcciones discursivas:

[La] discusión de políticas y opciones legales para una mejor protección de las expresiones de culturas tradicionales debe ser guiada, en la medida de lo posible, por las necesidades reales articuladas por grupos indígenas y comunidades locales y, lo más importante, por sus propias experiencias con el sistema de propiedad intelectual (Janke, 2003, p. 3). ${ }^{40}$

Es primordial, por lo tanto, que las particularidades culturales de los pueblos puedan ser protegidas a través de un marco jurídico que nazca de la confluencia de las nociones tradicionales y del derecho occidental.

\footnotetext{
39 "[...] an apartheid of the mind".

40 "Discussion of policy and legal options for the improved protection of expressions of traditional cultures should be guided as far as possible by the real needs articulated by Indigenous and local communities and, most importantly, their actual experiences with the intellectual property system".
} 
En este sentido, la noción de autenticidad que discutíamos previamente puede justamente ser colegida a aquella de propiedad. A pesar de que como hemos mencionado, el arte en general y la música en particular son difícilmente confinables dentro de las fronteras políticas modernas, la autenticidad introduce el derecho - una autoridad moral y/o estética- de uso exclusivo de ciertos elementos constitutivos de las muestras artísticas: aquellas expresiones que hacen parte de una cultura tradicional serán auténticas sólo al ser producidas por ésta y por lo tanto, toda reproducción no conforme podría ser impugnada. Más importante aún, esta noción otorga la potestad a las comunidades de autorizar o no cualquier trabajo derivado, creación o reproducción, que consideren que perjudica su imagen u ofende sus creencias. En cierto sentido, sería una manera de patentar "moralmente" las muestras artísticas que hacen parte del entramado social de una comunidad.

Esta idea de propiedad podría entonces ser utilizada para contrarrestar algunas de las amenazas que se desprenden de apropiaciones potencialmente perjudiciales, que crean y diseminan estereotipos o que dan lugar a fenómenos de transculturación. Como señala Young, en este contexto, la asimilación cultural es la principal amenaza: “La apropiación cultural pone en peligro las culturas [...] cuando sus miembros utilizan extensivamente elementos de otras culturas. 0 , como a menudo es el caso, cuando el lenguaje, las creencias y los gustos son impuestos a una cultura desde afuera" (2008, p. 153). ${ }^{41}$ La noción de propiedad puede entonces resultar útil si de esta manera se restituye a los pueblos aborígenes el poder de circunscripción sobre las prácticas artísticas y sus modos y lugares de creación, su reproducción total o parcial, sus modos de interpretación, etc. Las comunidades tendrían de esta manera la capacidad de evitar las deformaciones de sus expresiones artísticas, teniendo en cuenta que la cualidad estética en tanto que obra artística y su autenticidad en tanto que resultado de la construcción cultural son sus más importantes atributos.

Como modelo de esta postura podríamos citar el caso de la tribu aborigen norteamericana Hopi que en 1994, basándose en una ley aprobada por el congreso norteamericano, ${ }^{42}$ exigió a numerosos museos del país la restitución de todos los documentos relativos a su etnia -publicados o no-, y especialmente fotografías, grabaciones e ilustraciones de ritos religiosos.

\footnotetext{
41 “Cultural appropriation endangers a culture [...] when its members borrow too extensively from others. Or, as is sometimes the case, language, beliefs, and tasted are imposed on a culture from without".

${ }^{42}$ La ley federal denominada Native American Graves Protection and Repatriation Act (NAGPRA), promulgada en 1990. La ley establece un cuadro legal que constriñe a las agencias e instituciones federales a devolver los artículos culturales pertenecientes a las tribus aborígenes que así lo soliciten (Brown, 1998).
} 
Otros grupos indígenas -apaches especialmente- siguieron este ejemplo y reivindicaron por su parte el poder exclusivo de decisión sobre cualquier tipo de expresión cultural, entre las que contaban imágenes, ceremonias, músicas, símbolos, creencias, concepciones, objetos físicos y espirituales, incluyendo las representaciones que de éstas hacían los outsiders (Brown, 1998). Este caso nos muestra la conjunción entre el derecho ordinario y una consideración pragmática de la autenticidad que da como resultado una protección efectiva de las prácticas indígenas.

Es evidente que esta postura abre una serie de interrogantes de tipo práctico: ¿Cómo pueden demostrar las comunidades la tradición de sus expresiones? ¿Con qué mecanismos serán éstas juzgadas? ¿Qué formas de restitución o de veto pueden ser contempladas? ¿Cómo y quién verifica la validez de las alegaciones? ¿Quién tiene la autoridad para presentar un recurso de este tipo? Las cuestiones ontológicas son todavía más complejas: ¿Las poblaciones indígenas pueden tener un régimen jurídico especial sin afectar las libertades personales y la percepción de una justicia objetiva? ¿Es posible ampliar la concepción occidental de originalidad y de propiedad intelectual? ¿Cómo equilibrar el poder económico occidental y la autonomía indígena? ¿Qué determina la "tradición” de una expresión? ¿En qué momento una expresión individual deja de corresponderse con la cultura en la cual se originó? ¿Cómo conciliar estos derechos con el gobierno de "la mayoría”? ¿La libertad creativa y el éxito estético están por encima de cualquier consideración moral?...

La complejidad de esta cuestión se ve reflejada en la dificultad que han tenido entidades transnacionales como la WIPO o la UNESCO para lograr que sus disposiciones y conceptos encuentren una aplicación en las legislaciones locales en materia de derechos de autor y propiedad intelectual. Los países occidentales son reticentes a limitar las concesiones hechas a algunos sectores de su población incluso a costa de desconocer lo que consideramos derechos de las comunidades aborígenes. Nosotros creemos que si el mundo occidental quiere corresponderse con sus postulados de libertad, pluralismo y tolerancia, deberá aceptar y dialogar con concepciones diversas del mundo en lugar de reducirlas a una tipología de mercado y supeditarlas a éste. Así como los territorios indígenas ancestrales han logrado ser legalmente autónomos, los saberes biológicos tradicionales tutelados, los objetos aborígenes restituidos y el derecho consuetudinario reconocido, creemos que el derecho a determinar el uso de las expresiones musicales tradicionales por parte de las comunidades que las originan es factible -y deseable- dentro del derecho occidental, si se articula con las comunidades mismas y se respeta la propiedad que éstas tienen sobre sus prácticas culturales. 


\section{Bibliografía}

" Adorno, T. (2001). Le caractère fétiche dans la musique. Paris: Éditions Allia.

" Arom, S. y Martin, D.-C. (2015). L'enquête en ethnomusicologie. Préparation, terrain, analyse. Paris: Vrin.

»Aubert, L. (2005). Les passeurs de musiques: Images projetées et reconnaissance internationale. En Musiques migrantes: de l'exil à la consécration (pp. 110-129). Genève: Musée d'ethnographie.

»Borel, F. (1996). De l'anthropologie de la musique à l'ethnomusicologie visuelle. Cahiers d'ethnomusicologie, 9, 289-312.

» Brown, M. (1998). Can Culture be Copyrighted? Current Anthropology, 39(2), 193-222.

» Bsumek, E. (2016). Navajos Fight to Protect Their Brand. Pacific Standard. Recuperado de https://psmag.com/news/navajos-fight-to-protect-theirbrand

» Busoni, F. (1910). Abbozzo di una nuova estetica della música. Lipsia: InselVerlag.

»Eliot, T. S. (1961). Notes Towards the Definition of Culture. London: Faber and Faber limited.

》 Gruzinski, S. (2002). La pensée métisse. Paris: Éditions Fayard.

»Hémond, A. (2013). Artistes novateurs et création communautaire: Un exemple d'invention de la tradition au Mexique. En A. Dupuis (Dir.), Ethnocentrisme et Création (pp. 350-370). Paris: Éditions de la Maison des sciencies de l'homme.

» Janke, T. (2003). Minding Culture: Case Studies on Intellectual Property and Traditional Cultural Expressions. Geneva: World Intellectual Property Organization.

» Jaszi, P. (2017). Protecting Traditional Cultural Expressions - Some Questions for Lawmakers. Wipo Magazine, 4. Recuperado de https://www. wipo.int/wipo_magazine/en/2017/04/article_0002.html

» Knyt, E. (2010). How I Compose: Ferruccio Busoni's Views about Invention, Quotation, and the Compositional Process. The Journal of Musicology, 27(2), 224-264.

» Lecomte, H. (2005). Deux ou trois choses que je sais d'elles.... En L. Aubert (Ed.), Musiques migrantes: de l'exil à la consécration (pp. 130-147). Genève: Musée d'ethnographie.

»Mallet, J. (2002). "World Music" Une question d'ethnomusicologie? Cahiers d'Études Africaines, 42(168), 831-852.

» Martel, F. (2010). Mainstream: enquête sur cette culture qui plaît à tout le monde. Paris: Éditions Flammarion. 
» McCann, A. (1998). Traditional Music and Copyright - The Issues. Limerick: Irish World Music Centre, University of Limerick.

»Molino, J. (2009). Le singe musicien: essais de sémiologie et d'anthropologie de la musique. Arles: Actes SUD / INA.

» Moore, R. (2002). Música y mestizaje: revolución artística y cambio social en la habana. 1920-1940. Madrid: Editorial Colibrí.

»Ochoa, A. M. (2003). Músicas locales en tiempos de globalización. Buenos Aires: Grupo editorial Norma.

» Rose, J. (2016). Biopiracy: When Indigenous Knowledge is Patented for Profit. The Conversation. Recuperado de http://theconversation.com/ biopiracy-when-indigenous-knowledge-is-patented-for-profit-55589

» Yazzie, E. (2008). Protection of Navajo Sacred Objects. Tesis de maestría en Indigenous Nations Studies: University of Kansas.

»Young 0. J. (2008). The Cultural Appropriation and the Arts. Oxford: Blackwell Publishing Ltd.

» Young O. J. (2009). “Nothing Comes from Nowhere”: Reflections on Cultural Appropriation as the Representation of Other Cultures. En J. O. Young y C. G. Brunk (Eds.), The Ethics of Cultural Appropriation (pp. 268-289). New Jersey: Wiley-Blackwell.

»Zanetti, V. (2005). La nécessaire reconnaissance des milieux traditionnels dans l'apprentissage des percussions ouest-africaines. En L. Aubert (Ed.), Musiques migrantes: de l'exil à la consécration (pp. 100-109). Genève: Musée d'ethnographie.

"Zemp, H. (1996). The/An Ethnomusicologist and the Record Business. Yearbook for Traditional Music, 28, 36-56.

\section{Biografía / Biografia / Biography}

\section{Sebastian Olave Soler}

Realizó la maestría en Teoría y práctica de las artes en la Universidad de Aix-Marseille y es doctorando en Historia y cultura de mundos iberoamericanos contemporáneos en la Universidad Sorbonne-Université. Cursó estudios en composición e historia y cultura de la música en el Conservatorio de la ciudad de Bordeaux, Francia y en la Universidad de los Andes de Bogotá, donde además fue profesor asistente en cursos de apreciación de músicas populares. 